he identified included anisic, veratric, 3,4,5-trimethoxybenzoic, 4-methoxyisophthalic and isohemipinic acids.

The first paper presented on the second day was by Dr. J. C. Hughes (Norwich) and carried on the theme of humic acids, since it dealt with black and brown pigments formed in the potato after cooking or as a result of enzyme action. Production of the black pigment, an iron-chlorogenic acid complex, in cooked potatoes was greatly affected both by biochemical factors in the potato and by the environmental conditions in which the potato was grown; it could largely be prevented by adding eitric acid to the cooking water. The level of browning, on the other hand, is determined principally by the amount of substrate (tyrosine) and not the amount of enzyme (phenolase) in the potato. Turning from vegetable to flower pigments, Prof. E. Bayer (Tübingen) then described his work on naturally occurring anthocyanin metal complexes. Protocyanin, the natural chelate in cornflowers, he showed, can be split to cyanin, polygalacturonic acid, iron and aluminium. He pointed out that the reason why eyanin, present in red roses, would not complex with metal to give a blue colour was because chelating metals in these petals are not freely available, as they are bound to other substances of higher complex stability.

Anthocyanin pigments occur widely in leaves as well as flowers of higher plants and are abundantly present, for example, in leaves of the Asiatic Coleus species from which the popular ornamental plants are derived. However, Prof. H. Eugster (Zurich), in examining the red pigments on loaves of East African Coleus spp., found, not anthocyanins, but some new types of quinonoid pigments. The structures of two, coleon $A$ and $B$ from Coleus ignarius (fam. Labiatae), proved relatively easy to determine; $A$ is a 2,5-hydroxynaphthaquinone with an isoprenoid attachment and $B$ is a related hydroquinone. Fuerstion, from Fuerstia africana (also Labiatae), proved to be unusually labile, being sensitive to acid bases and heat, but, by very skilful experimentation, Prof. Eugster had been able to show that it was a methylene-quinone, somewhat related in structure to pristimerine.
Yellow xanthone pigments were the subject of the next paper by Dr. J. C. Roberts (Nottingham), who surveyed their occurrence in flowering plants (nine families), in fungi (three genera) and in lichens (one genus). He described methods of structural determination, and dealt specifically with tho identification of sterigmatocystin from Aspergillus versicolor and mangiferin from Mangifera indica. The latter xanthone has a $C^{\prime}$-glucosyl attachment and it thus formed a natural bridge to the next paper on naturally occurring $C$-glycosyl compounds by Prof. L. J. Haynes (Jamaica). He described the nuclear magnetic resonance evidence which supported $C$-glycosyl structures for mangiferin and related compounds, and outlined recent research on a new $C$-glucosylchromone in bitter aloes. 'The final paper by Dr. R. M. Horowitz (Pasadena) was on $C$-glycosylfavones, and in it he presented nuclear magnetic resonance evidence which proved that vitexin was 8- $C$-glucosylapigenin, isovitexin 6- $C$-glucosylapigenin and the lucenins 6,8-di- $C$-glucosyl-luteolins. $\mathrm{He}$ used similar data in very elegant fashion to show that the xylose in a D-xylosylvitexin (isolated from oranges) was attached by a $\beta 1 \rightarrow 2$ link to the 8-glucosyl residue, and that a $p$-hydroxybenzoic acid derivative of vitexin was similarly constituted.

The meeting ended with short reports on the xanthones in Kielmeyera spp. (M. T. Magalhaes, Brazil) and in Calophyllum spp. (F. Scheinmann, Salford), on the quinones in Tabebuia ipé (A. R. Burnett, Aberdeen), on a novel yellow fungus pigment from Paxillus involutus (R. L. Edwards, Bradford), on umbelliferone biosynthesis (D. J. Austin, Glasgow), and on the Aspergillus hydroxylating system (S. M. Bocks, Oxford). It was clear from this symposium that plant pigments continue to provide a challenge to the skill and ingenuity of the organic chemist and that problems remain which will take much effort to solve, unless dramatically new techniques become available. The attraction of their colour will always ensure abundant interest in the chemistry of these fascinating substances.

J. B. Harborne

\title{
DESIGN METHOD
}

\begin{abstract}
THE OXFORD DICTIONARY lists many different interpretations of the word 'design' used either as noun or verb, but it now has a new meaning in its own right: a subject to be studied for its own sake, regardless of any primary discipline involved. Design as a fundamental concept is on its way to becoming a science. In the sense of producing now and useful commodities of all kinds, it is seen as a major challenge to human ability. "The better understanding of the problems involved provides a task for the behavioural scientists. The better development of designers requires careful thought by management." The theoretical and practical values of pioneering inter-disciplinary thinking in the broad field of design had to be tested. That the task has proved more than successful is attested by the symposium sponsored by the Design and Innovation Group of the University of Aston in Birmingham (designate), convened in Birming. ham during September $21-23$, of which a copy of the preprints of the papers presented is now available*.

This volume undoubtedly brings together, in a sub. stantial way and for the first time in Great Britain, the general trend of thought about tho nature and problems of design by many different people in many walks of life having wide experience in this field. Thirty papers dealing with design from inception to realization and utilization are included. Breadth of coverage is shown by the wide range of technologies and sciences represented; these are

* Design Method Symposium, University of Aston in Birmingham Designate (Organized by the Design and Innovation Group.) Pp. 322. (Butterworths, London, 1965.)
\end{abstract}

architecture, behavioural sciences, chemical engineering, electrical engineering, electronics, ergonomics, fuel technology, information science, instrument technology, mechanical engineering, metallurgy, philosophy, physics, production engineering, psychology and sociology.

As if to emphasize the concept of the building and ultimate evolution of design science, the symposium is appropriately divided into six successive sections: (1) the design process; (2) human needs and satisfaction; (3) stages of design; (4) practical design and techniques; (5) realization; (6) design and management.

The design process is concerned with overviows of the total process of design. It is illustrated by five papers: "Design Methods Reviewed", by J. C. Jones; "Some American Viows on the Design Process", by R. J. McCrory; "A Survey of Design Methodology", by W. E. Eder; "Proparatory Work for Research into Electronics Design", by H. V. Beck; and "Design Science", by S. A. Gregory. On the bases of experience in these fields, it is deduced that the time is ripe for research into design and the establishment of design science as an aid to the practical designer.

"All technological design attempts to fulfil some human neod or provide somo satisfaction." The section on human needs and satisfaction is concernod with establishing the concepts involved and exploring ways of finding out or measuring human needs. Herein, to guide constructive thinking, are a furthor five papers: "Design and Human Satisfaction", by W. H. Mayall; "Invention, Design and Markot Research", by A. F. Stobart; "Sociology and 
Design", by A. M. Penny; "Ergonomics and Design", by B. Shackel; and "Choosing and Evaluating", by A. G. Pleydell-Pearce.

The foreword to the section on stages of design reads: "From the perception of need it is possible to set down the design process in successive stages. These stages are not intrinsically isolated but may be conveniently separated for the purpose of description and study. In practice the operations involved in the sequence continually re-define each other until a solution satisfactory for the particular circumstances arrives." In support of this dictum are again five papers: "The Elements of Design", by R. D. Watts; "Information for Design", by J. E. L. Farradane "Patterns", by A. D. Newman; "Creativity", by G. H. Broadbent; and "Design and Decision", by S. A. Gregory.

The theme of practical design and techniques is an analysis of the methods that designers are finding useful and consideration of progress in application of now ideas. In this section we get down to what may be termed the day-to-day function of the designer in certain fields, rather than the more philosophical aspects of his work. "Designers, in reporting their work, tend to concentrate upon the more technical aspects of the task." But there is more to it than this, as is apparent from these papers: "A Practical Design-An Oil Burner for Large Watertuhe Boilers", by A. M. Needham; "The Implications of Economics in Engineering Design", by A. P. Shahbenderian; "Models", by C. Hulse; "The Use of a Digital Computer in Design Offices", by K. C. Parton; and "Fundamental Design Mothod", by E. Matchett and A. H. Briggs, an interesting case of how a combination of systematic method and psychological stimulation contributed to the production of a useful design.

In the section on realization, the underlying motive is that eventually all practical designs, if successful, must come to a material embodiment. This demands study of the interaction of function, fabrication techniques, number and complexity of products. In this concept such inter. action affects assembly, reliability, maintenance, best use of space, and overall cost. All decisions made in this category must be communicated to everybody involved, to make this goal of realization truly effective. To show how this can be done, F. L. Ellis contributes a paper on
"Design Realization"; "Selection of Materials" is discussed by A. L. Davies; a paper by C. T. Corney entitled "Reliability and Maintenance" is followed by one on "Design of Materials", by S. A. Gregory, while a welcome note on "New Ideas in the Drawing Office" is struck by P. McMullen.

The final section on design and management probably goes to the root of the whole project of a dosign science, in that it seeks to equate formulation of policy, operation and motivation of working groups, effect of major organization on design, and methods of evaluating the effectiveness of design organizations as a whole, as a mattor of fundamental concern. The exponents in this argument are B. T. Turner, in his paper on "Design Policy Formulation"; R. Davis in his "Innovative Design is a Policy Function of Directorship", wherein it is emphasized that relationship between design and the whole enterprise of which it forms part must be carefully established and the overriding policy laid down for all concorned to appreciate and act on; I. M. Ross discusses "Effect of Organizational Procedures on Design"; M. E. Peplow, "Design Acceptance"; and finally C. H. Buck, who has written an admirable summary of the proceedings at the symposium, enclosed with this volume, contributes his share on the vital subject of "Communication".

There is no doubt that this symposium, and what will follow from it, breaks new and profitable ground. Pressure towards a rational analysis of activities involved in the process of design has, of recent years, steadily increased. Previously in Great Britain, stimuli in this direction were the outcome of the Feilden Report (Nature, 206, 643, 1965), the 1962 Conference on Design Methods, and the Scarborough Conference on Teaching of Engineering Design in 1964. This volume shows that we have gone a long way from the impetus of those deliberations and in a comparatively short time. It is the intention of Butterworth and Co. (Publishers), Itd., to issue a version of the Proceedings, together with discussion, suitably edited by S. A. Gregory, on behalf of the Design and Innovation Group, which will make available in durable form the woalth of new information and ideas implicit in and realized by this important symposium: thus is a new science born.

\title{
VALIDITY OF RADIOCARBON DATES ON BONE
}

\author{
By DR. M. A. TAMERS and F. J. PEARSON, jun. \\ Department of Chemistry, Instituto Venezolano de Investigaciones Científicas, Caracas, Venezuela, and Radiocarbon Dating \\ Laboratory, University of Texas, Austin
}

\begin{abstract}
A SURVEY of the scientific literature reveals the fact that carbon-14 dates on bone often do not accord with independent estimates of the site ages. Bone dates are generally regarded as considerably less reliable than determinations using charcoal, wood, or other materials with large carbon contents (except shell). Most laboratories are in agreement that, whenever possible, bone should not be used for radiocarbon dating.

However, in many instances important finds are made where the only datable material available is bone. A problem illustrating this is tho well-known palaeo-indian site, Muaco, in Venezuela ${ }^{1}$, which is a kill site. No charcoal was found associated with the animal bones and human artofacts. Two specimens of the bones have given carbon14 ages of $16,375 \pm 444$ B.P. and $14,300+500$ B.P. ${ }^{2}$, which are the oldest dates associated with human habitation in South America. Furthermore, these dates fall within a period (between 12,000 and at least 25,000 years ago) in which there was little or no human activity in North America, as evidenced by the scarcity of radiocarbon dates of these ages. A serious controversy has
\end{abstract}

arisen as to whether the Murco site is really as ancient as the radiocarbon dates indicate or whether it is possible that radiocarbon dating of bone can give falsely old ages.

The validity of radiocarbon dates on bone is investigated by determining the natural carbon-14 concentrations of samples of known age, that is, historically dated specimens or those found associated with charcoal or other materials known to give reliable radiocarbon dates. Several radioearbon dating laboratories have measured known-age bone samples with varying rosults. Recently, Berger. Horney and Libby ${ }^{3}$ have concluded that, with an aciddissolving preliminary treatment, bones will be capable of reliable radiocarbon ages. Dates on bone not so treated can give incorrect ages, but there is no indication of evidence that the errors could be such as to make the bone samples appear older than they really are (which is the question in the Muaco site) and insufficient data to permit conclusions as to the extent of the errors involved. Furthermore, it seems reasonable to investigate in more detail the reliability of the special preliminary treatment, used to 